\title{
RESCRIEREA ISTORIEI LA MILAN KUNDERA
}

\section{Marcela-Cristina OȚOIU*}

\section{Rewriting History in Milan Kundera}

\begin{abstract}
The novels of Milan Kundera trace the possibility of rewriting history at both the individual level and within collective memory. The erasure of history in totalitarian society sets off with the erasure of the individuals' social and professional identities, both in the present and in the past. This abusive practice carries on at the level of the whole collectivity by the manipulation of the present by means of censorship and distortion of information. It eventually moves backwards to rewrite large swathes of history.

The massive encroaching of totalitarian practice onto the individual and collective indentity ends up with a systematic control of memory. This is why one of the main duties of those who fight totalitarianism is the so-called devoir de mémoire (duty of memory), viewed as an instrument of one's struggle to reinstate Truth.
\end{abstract}

Keywords: history, rewriting, erasure, revision, forgetfulness

\section{Istorie contemporană la Kundera}

De la La Plaisanterie până la L'immortalité, aproape fiecare din romanele lui Kundera conţine rapeluri la istoria recentă sau la situaţia politică a țării sale, Cehoslovacia. Multe din acestea se referă la istoria Primăverii de la Praga şi a represiunii acesteia.

În prima secvenţă din Le livre du rire et de l'oubli, dispariţia lui Clementis din poza din 1948 are paralele cu suprimarea din viaţa publică a lui Mirek în anii ce au urmat invaziei sovietice. În secvenţa a treia, Les anges/Îngerii, ,după ce ruşii au ocupat ţara mea," naratorul, identificat cu Milan Kundera, e concediat (,,pentru că am spus ceva ce nu trebuia să spun”), îşi pierde dreptul de semnătură, iar cei ce-l ajută sunt hărţuiţi de poliţia secretă. Şi aici avem o paralelă între 1968 şi 1950, anul de vârf al terorii staliniste: episodul execuţiei poetului suprarealist Zavis Kalandra, „declarat inamic al poporului."

În a patra secvenţă, soţul Taminei ajunge pe lista neagră a poliţiei secrete, probabil fiindcă „foştii colegi au dat declaraţii publice în care îl calomniau şi-1 condamnau" şi părăseşte ilegal ţara, murind în exil.

\footnotetext{
* Lector univ. dr., Universitatea Tehnică din Cluj-Napoca, Centrul Universitar Nord din Baia Mare, Facultatea de Litere, str. Victoriei, nr. 76, Baia Mare (marcela.otoiu@cunbm.utcluj.ro).
} 
Al cincilea episod, Litost, deşi se situează temporal înaintea anului 1968, conţine o prolepsă ce trimite la timpul (ulterior) al naraţiunii, anul 1977:

Suntem în toamna anului 1977, țara mea somnolează deja de nouă ani în dulcea şi viguroasa îmbrăţişare a Imperiului rus, Voltaire a fost exclus din universitate, iar cărţile mele ... au fost închise în cine ştie ce pivniţă a Statului. ${ }^{1}$

Şi în L'immortalité, chiar dacă e primul roman kunderian a cărui scenă nu e Cehoslovacia, naratorul analizează radicalismul tinerilor cehi din 1948, discută prezenţa cuvântului „luptă” în limbajul comunist, iar o cehoaică întoarsă în ţară în 1969 ,şi-a găsit ţara ocupată de armata rusă."

Deşi se remarcă omniprezenţa lor în scrisul lui Kundera, imaginile politicului şi în special cele ale Primăverii de la Praga sunt prezentate din perspectiva literatului. Kundera e mai interesat de destinele individuale şi de impactul brutal al politicului asupra acestora, decât de istoria politică în sine. În fond, Kundera s-a apărat mereu de eticheta de disident politic pe care i-au aplicat-o occidentalii, preferând rolul unui „disident cultural a cărui misiune e să-şi alerteze contemporanii de prezenţa unor ameninţări mai adânci sau mai ample decât comunismul,"2 descriindu-se pe sine drept „un hedonist prins în capcană într-o lume politizată la extrem., ${ }^{3}$

\section{Ştergeri, corecturi, rescrieri}

Imaginile ştergerii, ocultării, radierii, ca şi cele ale corecturii, retuşării şi rescrierii sunt frecvente în cărţile lui Kundera. Acestea pot fi publice, mergând de la ştergeri şi modificări de fotografii (dispariţia lui Clementis din poza Glorioasei revoluţii) ori de la alterări de imagini publice (falsele mărturii depuse de colegi împotriva lui Pavel) până la eliminarea personalităţilor culturale şi ştiinţifice din viaţa publică (multiplele referiri făcute de Kundera la interdicţia dreptului său de semnătură, ori prohibiţiile profesionale suferite de Mirek, Voltaire şi alţii); sau pot fi private, fiind ori rod al uitării (Tamina văzându-şi preţioasele amintiri despre soţul mort dispărând sau fiind evacuate de imaginea respingătorului Hugo), ori false anamneze (falsa amintire a Mamei despre poezia recitată la festivitatea din tinereţe).

\footnotetext{
1 «Nous sommes à l'automne 1977, mon pays sommeille depuis neuf ans déjà dans la douce et vigoureuse étreinte de l'empire russe, Voltaire a été exclu de l'université et mes livres [...] ont été enfermés dans quelque cave de l'État. » - Milan Kundera, Le livre du rire et de l'oubli, traduit du tchèque par Fr. Kérel, Gallimard, Paris, 1985, p. 197.

2 "cultural dissident whose mission is to alert his contemporaries to the presence of broader or deeper menaces than just communism" - Yvon Grenier, "Milan Kundera on Politics and the Novel," in History of Intelectual Culture, vol. 6, no. 1, 2006, p.2.

${ }^{3}$ « un hédoniste piégé dans un monde politisé à l'extrême»-citat în Grenier, op. cit., p. 1.
} 
Ele se referă frecvent la (a) uitarea ca proces natural şi inevitabil, (b) alteori la dorinţa imposibilă a omului de a-şi controla şi modifica trecutul personal; (c) alteori la intervenţia literatului în arta lui (corectura ca un drept inalienabil al romancierului); (d) deseori la acţiunea brutală a forţelor politicului (poliţia secretă, cenzura, dar şi „,colectivele de oameni ai muncii” captive politic).

S-ar putea trasa o paralelă între aceste ştergeri şi ocultări, pe de o parte, şi revizionismul istoriografic, pe de altă parte. Paralela ar fi motivată de distincţii între ştergerile „,bune”, legitime, sau chiar salutare (cum ar fi ştergerea amintirilor prea banale) şi ştergerile „rele”, nelegitime şi criminale (cenzura şi damnatio personae).

Totuşi, un anumit pasaj din Le livre du rire et de l'oubli are o valoare ambiguă. Vorbind despre Zdena, fosta iubită care are încă scrisorile pe care el vrea să le distrugă, Mirek înţelege că

[d]acă el voia să şteargă fotografiile vieţii sale, nu era pentru că n-o iubise, ci pentru c-o iubise. O ştersese, pe ea şi iubirea lui pentru ea, [...] până o făcuse să dispară, tot aşa cum secţia de propagandă a partidului îl făcuse să dispară pe Clementis din balcon [...]. Mirek rescrie Istoria exact ca şi partidul comunist, ca toate partidele politice, ca toate popoarele, ca orice om. $^{4}$

Bărbatul ajuns într-un moment de criză (e urmărit de poliţia secretă, are interdicţie profesională, ,numele lui a fost şters” şi se simte „,ca un fragment de vid") şterge urmele fizice ale unei iubiri trecute şi compară acest act cu rescrierea istoriei practicată de comunişti. Mai mult chiar, acest revizionism ilegitim pare să fie pus pe acelaşi plan cu dorinţa omenească de uitare a unui trecut problematic. Aceasta poate da senzaţia că-i absolvă pe corectorii Istoriei în numele unei tendinţe omeneşti de a ajusta trecutul prin uitare sau înfrumuseţare.

Lucrurile trebuie însă nuanţate. Mirek nu banalizează răul revizionismului făcându-l să pară uman. Ci mai degrabă el, trăind drama propriei sale ştergeri din societate, îşi vede anonimizarea şi ruperea de propriul său trecut ca pe o tragedie de dimensiunile celei produse de comunişti în ţara sa. Pradă pesimismului (care va fi confirmat de arestarea sa la sfârşitul secvenţei), el generalizează şi vede ruperea de trecut ca o trăsătură a tuturor oamenilor din jurul lui.

Ne vom opri în cele ce urmează la câteva tipuri de alterare a trecutului, aşa cum le-am enumerat anterior: (1) uitarea ca proces natural, (2)

\footnotetext{
${ }^{4}$ «S'il voulait l'effacer des photographies de sa vie, ce n'était pas parce qu'il ne l'aimait pas, mais parce qu'il l'avait aimée. Il l'avait gommée, elle et son amour pour elle, [...] jusqu'à la faire disparaître comme la section de propagande du parti avait fait disparaître Clementis du balcon [...]. Mirek récrit l'Histoire exactement comme le parti communiste, comme tous les partis politiques, comme tous les peuples, comme l'homme. »- Kundera, Livre du rire..., p. 41.
} 
modificarea trecutului personal, (3) rescrierea manuscriselor de către artişti, (4) revizuirea istoriei de către ideologi şi istorici. De fiecare dată, vom încerca să aducem în discuţie trei criterii: (a) corespondenţa cu faptele, (b) caracterul liber sau impus al modificării, (c) efectul acesteia asupra comunităţii.

\section{1) Uitarea ca proces natural}

În L'ignorance, avem de a face cu o involuntară falsificare a trecutului datorată imperfecţiunii memoriei, a slabei ei capacităţi de a reţine lucruri. Astfel, când doi prieteni se întâlnesc şi deapănă amintiri, se dovedeşte că fiecare a reţinut altceva. Deficienţa memoriei face ca amintirile trecutului să se estompeze, iar fixarea unei amintiri să nu fie altceva decât un proces de condensare de imagini într-una singură. Este ceea ce face şi Josef din L'ignorance, care, vrând să-şi amintească chipul soţiei defuncte, vede mai multe expresii, mai multe zâmbete, fără să-l poată fixa pe cel adevărat. Orice efort de a resuscita trecutul, de a retrăi momentele importante, sunt zadarnice pentru el. Astfel, Josef devine conştient că încercarea de a-şi fixa pentru totdeauna amintirile devine ,un muzeu al obiectelor pierdute."

\section{2a) Rescrierea liberă a trecutului personal}

Chiar şi atunci când cineva îşi rescrie propriul trecut personal în deplină libertate, efectele acestui act pot fi diferite.

Am văzut cum Mirek doreşte să elimine urmele materiale ale iubirii lui pentru Zdena. Gestul pare paradoxal pentru cineva care pare obsedat de memorializarea propriei sale vieţi (,,îşi ţine cu grijă jurnalul, îşi păstrează corespondenţa, redactează rapoarte ale întâlnirilor"5). Pentru Mirek însă, gestul este legitim şi nu are o motivaţie etică (faptul că Zdena a devenit o activistă zeloasă şi o suporteră a invaziei sovietice e secundar), ci estetică, de eliminare a ,urâtei” Zdena din trecutul lui:

El avea cu viaţa sa acelaşi raport pe care-1 are sculptorul cu statuia sa ori romancierul cu romanul său. [...] Zdena se încăpățâna să rămână în primele pagini ale romanului [său] şi nu se lăsa ştearsă. ${ }^{6}$

Tot astfel, mama lui Karel din Le livre du rire et de l'oubli îşi corectează memoria deficitară, reinventând o amintire care o pune într-o lumină favorabilă. Dorinţa de a-ţi reinventa viaţa nu e una nefirească, fiindcă „omul ... n-are decât o viaţă şi... nu poate sa şi-o rectifice în vieţi ul-

\footnotetext{
5 « il tient soigneusement son journal, conserve sa correspondance, rédige les minutes de toutes les réunions »-Kundera, Le livre du rire..., p. 14.

${ }^{6}$ « Il avait avec sa vie le même rapport que le sculpteur avec sa statue ou le romancier avec son roman. [...] Zdena insistait pour rester dans les premières pages du roman et ne se laissait pas effacer. »-ibid.., p.25.
} 
terioare" şi - aşa cum crede Tomas din L'insoutenable légèreté de l'être „a nu putea să trăieşti decât o viaţă e ca şi cum n-ai trăi deloc." 7

În L'immortalité, o linie narativă distinctă se ocupă de relaţia dintre Goethe şi Bettina von Arnim. E o relaţie marcată de efuziuni insistente din partea tinerei romantice şi de reţinere din partea vârstnicului geniu. $\mathrm{O}$ frază suspectă a tinerei îi atrage atenţia naratorului: „Voinţa mea fermă e să te iubesc pe vecie." De aici naratorul înţelege adevărata miză a insistenţelor Bettinei: „între ei nu era vorba de dragoste, ci de nemurire." 8

Nemurirea de care vorbeşte Bettina, ne explică Kundera, nu are legătură cu credinţa religioasă în sufletul nemuritor, ci

e vorba deci de o cu totul altă nemurire, pământească, a celor ce vor rămîne după moartea lor în amintirea posterităţii. ${ }^{9}$

Aici Kundera lansează o teorie a celor două feluri de imortalitate:

Se cuvine să deosebim mica nemurire, amintirea omului în minţile celor care l-au cunoscut (...) de marea nemurire, însemnând amintirea unui om în minţile acelora care nu 1 -au cunoscut personal. ${ }^{10}$

Iar Bettina confirmă mai târziu că scopul ei este ca, folosindu-se de relaţia ei cu marele poet, să acceadă la marea nemurire. „Vreau să mă depăşesc pe mine însămi, să fiu o parte a istoriei, fiindcă istoria e memoria eternă,"11 declară ea solemn.

După moartea lui Goethe, Bettina, ajunsă la vârsta rememorărilor, e nemulţumită de caracterul reticent al corespondenţei lor. Şi atunci, ea „,̂ş̧i rescrise propriile sale scrisori," iar timp de trei ani "a corectat, a transcris, a adăugat" la epistolele lui Goethe. ${ }^{12}$ Nemulţumită de tonul condescendent al poetului, ea modifică tonalitatea acestuia :

astfel, „scumpa mea prietenă” deveni ,inimioară dragă” - dojenile erau îndulcite cu adaosuri măgulitoare şi alte fraze ajutătoare, menite să demon-

\footnotetext{
${ }^{7}$ « L'homme [...] n'a q'une vie et il ne peut [...] la rectifier dans des vies ultérieures. » « $\mathrm{Ne}$ pouvoir vivre qu'une vie, c'est comme ne pas vivre du tout». - Kundera, L'insoutenable légèreté de l'être, traduit du tchèque par François Kérel, Gallimard, Paris, 1984, p.19 şi 20.

8 «Ce dont il s'agissait n'était pas l'amour. C'était l'immortalité. » - Milan Kundera, L'Immortalité, Gallimard, Paris, 1993.

9 «L'immortalité dont parle Goethe n'a, bien entendu, rien à voir avec la foi en l'immortalité de l'âme. Il s'agit d'une autre immortalité, profane, pour ceux qui restent après leur mort dans la mémoire de la postérité »-ibid., p. 79.

10 « Il faut distinguer la petite immortalité d'un homme dans l'esprit de ceux qui l'ont connu, [...] et la grande immortalité, souvenir d'un homme dans l'esprit de ceux qui ne l'ont pas connu. »-ibid., p. 80.

11 «Aspirant à la grande immortalité, Bettine veut dire : [...] je veux me dépasser moimême, faire partie de l'Histoire, parce que l'Histoire est la mémoire éternelle. » - ibid., p. 248.

12 «Elle corrigeait, elle réécrivait, elle complétait. »-ibid., p. 115.
} 
streze puterea ei de Muză inspiratoare asupra poetului vrăjit. ${ }^{13}$

Dacă Bettina rescrie dovezile relaţiei cu Goethe, ea nu o face însă doar pentru a-şi vindeca eul rănit de răceala poetului. Miza ei e mai mare. Ea doreşte să fie recunoscută de posteritate ca „Muză inspiratoare” a marelui geniu. Ea publică această corespondenţă modificată într-un volum în 1835 . În acest punct, rescrierea ei încetează a fi „de uz intern” şi devine publică. Practic, Bettina modifică biografia lui Goethe şi, indirect, istoria literaturii germane. Chiar dacă falsul avea să fie descoperit în 1920, efectul de imagine este permanent: Bettina şi-a asigurat un loc în toate istoriile literare, în vreme ce soţia lui Goethe, adevărata lui inspiratoare, rămâne la imaginea de gospodină fadă, pusă în circulaţie tot de Bettina.

Ambele rescrieri ale propriului trecut - cea a lui Mirek şi cea a Bettinei - sunt practic falsificări ale faptelor. Ambele sunt acte liber consimţite. În schimb, în vreme ce Mirek n-ar afecta pe nimeni prin distrugerea corespondenţei lui amoroase, contrafacerile Bettinei au schimbat imaginea lui Goethe şi, indirect, istoria literară.

\section{2b) Ştergerea şi rescrierea forţată a destinelor individuale}

Rescrierea istoriei în totalitarism nu este doar o operaţiune post factum. Ea începe cu prezentul, cu cenzurarea presei şi intoxicarea mass mediei cu ştiri distorsionate. Ştergerea istoriei începe cu ştergerea identităţii profesionale şi sociale a indivizilor.

În Ceholsovacia „normalizării,” Legea 99 şi epurările care au urmat au afectat nu doar cei 150.000 de membri reformatori ai partidului, ci şi pe cei 500.000 de artişti, jurnalişti şi universitari, cărora li s-a interzis dreptul de a profesa şi care au fost trimişi „la munca de jos.” Ivan Klíma, unul din cei mai respectaţi prozatori cehi, a lucrat o vreme ca zilier la salubritate, experienţă memorabil surprinsă în romanul său Dragoste şi gunoi, unde îşi descrie astfel exilul intern:

În ultimii zece ani am trăit într-un ciudat fel de exil, urmărit de interdicţii şi supravegheat de paznici, uneori vizibili, uneori invizibili, şi alteori doar imaginaţi. Nu puteam să intru în viaţă decât ca un oaspete, ca un vizitator, sau ca un muncitor cu ziua... ${ }^{14}$

Kundera a trecut şi el prin experienţe similare. Concediat, lipsit de dreptul de semnătură, el devine o non-persoană:

\footnotetext{
13 «Aussi dut-elle en changer le ton : "ma chère amie" devint "mon cher coeur", les blâmes qu'il lui avait infligés se trouvèrent adoucis par des ajouts flatteurs, et d'autres ajouts firent entendre quel rôle d'inspiratrice et de muse Bettina avait su jouer auprès du poète fasciné »-ibid., p. 116.

${ }^{14}$ Ivan Klíma, Love and garbage, ediţie ebook, trad. Ewald Osers, Vintage, Londra, 2002. [1096] [p.20].
} 
Existenţa mea, existenţa unui om tăiat din istorie, din manualele de literatură şi din cartea de telefon este existenţa unui mort care bântuie. ${ }^{15}$

Singura cale de a avea o existenţă în spaţiul public al culturii este să scrie articole sub nume de împrumut, o cale care se va dovedi o fundătură periculoasă.

În L'insoutenable légèreté de l'être, Tomas, un chirurg reputat, scrie un articol „necorespunzător,” e hărţuit de poliţie, care-i cere o retractare publică, rezistă compromisului şi demisionează, ajungând spălător de vitrine. Era încă epoca în care ,persecuţiile în masă împotriva intelectualilor cehi trezeau încă „,un fel de euforie a solidarităţii.","16

Ştergerea biografiilor individuale e doar primul pas spre rescrierea istoriei. Aşa cum constată autorul la prima aniversare a invaziei, „numele celor care s-au ridicat contra propriei lor tinereţi sunt şterse cu grijă din memoria ţării, aşa cum se şterge o greşeală din caietul unui şcolar." pentru care comuniştii „,vor să şteargă din memorie mii de vieţi” este ca „să nu mai rămână decât timpul imaculat al idilei imaculate" a ţării cu comunismul. $^{18}$

Aparent mai puţin gravă, însă având consecinţe la fel de serioase, este manipularea perversă a mărturiilor celor excluşi din istorie. În L'insoutenable légèreté de l'être, Tereza, fotojurnalist la un cotidian praghez, arestată şi apoi eliberată, fotografiază cu frenezie scenele invaziei:

A trăit cele mai frumoase zile ale vieţii ei când fotografia soldaţii ruşi pe străzile Pragăi şi era expusă pericolului. ${ }^{19}[$ [...]

Ea îşi petrecu primele şapte zile ale Ocupaţiei într-un fel de transă care semăna cu fericirea. Era pe stradă cu un aparat foto şi-şi împărţea filmele jurnaliştilor străini care se băteau pentru ele. ${ }^{20}$

Spectacolul rezistenţei surprins de Tereza e în spiritul tineresc al revoltelor studenţeşti ale anului 1968:

\footnotetext{
15 «Mon existence, l'existence d'un homme rayé de l'histoire, des manuels de littérature et de l'annuaire téléphonique, d'un homme mort... »-Kundera, Le livre du rire..., p.98.

16 « les persécutions en masse contre les intellectuels... comme une sorte d'euphorie de la solidarité »-ibid., p. 248-9.

17 « Les noms de ceux qui se sont soulevés contre leur propre jeunesse sont soigneusement gommés de la mémoire du pays comme une faute d'un devoir d'écolier. »-ibid., p. 30.

18 «Ils voilaient effacer de la mémoire des centaines de vies pour qu'il ne reste que le seul temps immaculé de l'idylle immaculée. »-ibid., p. 44.

${ }^{19}$ «Elle avait vécu les plus beaux jours de sa vie quand elle avait photographié les soldats russes dans les rues de Prague et qu'elle s'était exposée au danger. »- Kundera, L'insoutenable légèreté de l'être, traduit du tchèque par Fr. Kérel, Gallimard, Paris, 1984, p. 38.

${ }^{20}$ «elle passa les sept premiers jours de l'occupation dans une sorte de transe qui resemblait presqu'à du bonheur. Elle était dans la rue avec un appareil photographique et distribuait ses pellicules aux journalistes étrangers qui se battaient pour en avoir. »ibid., p. 37.
} 
Era o sărbătoare ameţitoare a urii. Oraşele Cehiei s-au umplut de mii de afişe desenate de mână înţesate de inscripţii sarcastice, de epigrame, de poeme, de caricaturi ale lui Brejnev şi ale armatei sale de care toată lumea îşi bătea joc ca de o trupă de bufoni analfabeţi. ${ }^{21}$

Unele din pozele făcute de Tereza sfârşesc în mâna StB-ului (poliţia secretă) care le foloseşte pentru a-i identifica pe participanţi. Astfel, Tereza, care voise să suprindă imaginea oamenilor cerându-şi dreptul la libertate, devine instrumentul involuntar al privării lor de libertate.

\section{3) Rescrierea textelor de către artişti}

Atunci când vrea să-şi corecteze trecutul, Mirek invocă unul din privilegiile artistului şi o face aproape cu invidie:

Dreptul intangibil al romancierului este să-şi poată relucra romanul. Dacă începutul nu-i place, îl poate rescrie sau suprima. ${ }^{22}$

Mai neobişnuită este situaţia lui Agnes, protagonista romanului L'Immortalité. Faptul că acest roman îl are ca narator explicit pe Kundera pare să-i confere un statut autobiografic. Aşteptările cititorului sunt ca acest statut nonficţional să se răsfrângă asupra personajelor. Kundera ne face însă martorii genezei personajului său, inspirat de gestul tineresc al unei femei mai în vârstă:

Aşa cum Eva se trage din coasta lui Adam, aşa cum Venus s-a născut din spuma mării, Agnes a izvorît din gestul acelei doamne sexagenare [...] Gestul ei a trezit atunci în mine o imensă şi neînţeleasă nostalgie, iar această nostalgie a dat naştere personajului căruia eu i-am dat numele de Agnes. $^{23}$

Într-un gest de ridicare metaficţională a cortinei, Kundera ne dezvăluie practic momentul când s-a hotărât să transforme o femeie oarecare într-un personaj al unei ficţiuni. Asistăm la gestul prin care, ignorând totul despre necunoscuta aceea, el o boteză Agnes, o licenţă poetică, desigur (fiindcă nu ştim cum o chema pe femeia reală). Deşi aşteptările cititorului sunt oarecum înşelate de acest gest, totuşi nu e nimic nelegitim în această declaraţie explicită a totalei libertăţi a autorului asupra lumii sale fictive.

21 «C'était la fête enivrante de la haine. Les villes de Bohême se covraient de milliers d'affiches peintes à la main rehaussées d'inscriptions sarcastiques, d'épigrammes, de poèmes, de caricatures de Brejnev et de son armée dont tout le monde se moquait coome d'une troupe de clowns illetrés. »-ibid., p. 38.

22 «Un droit intangible du romancier, c'est de pouvoir retravailler son roman. Si le début ne lui plaçit pas, il peut le récrire ou le supprimer. » - ibid., p.25.

23 « De même qu'Ève est issue d'une côte d'Adam, de même que Vénus est née de l'écume, Agnès a surgi d'un geste de la dame séxagénaire [...]. Son geste a alors éveillé en moi une immense, une incompréhensible nostalgie, et cette nostalgie a accouchée du personnage auquel j'ai donné le nom d'Agnès. »-Milan Kundera, L'immortalité, p. 18. 


\section{4) Rescrierea istoriei}

În cartea sa Les Abus de la mémoire, Tzvetan Todorov atrage atenţia asupra relaţiei dintre regimurile totalitare din secolul al XX-lea şi fenomenul de ştergere a memoriei. El observă că practicile totalitare şi-au sistematizat controlul asupra memoriei, pe care au vrut să îl extindă chiar până la cel mai mic detaliu. ${ }^{24}$ Astfel, urmele trecutului sunt „ori şterse, ori cosmetizate şi transformate" ${ }^{, 25}$, minciunile luând locul realităţii, iar adevărul fiind ascuns şi nedifuzat. Istoria poate fi rescrisă astfel cu fiecare schimbare a echipei de conducere. Din această cauză, una din datoriile celor ce se opun totalitarismului este datoria memoriei, văzută ca instrument al luptei pentru (re)instituirea adevărului. Valorizarea memoriei îşi are rolul în reconstituirea trecutului, în restabilirea adevărului, chiar dacă este recunoscut faptul că memoria operează nu prin restituire integrală ci prin selecţie. Diferenţa majoră dintre modurile de operare ale memoriei, recunoscute ca imperfecte în ambele situaţii, este faptul că, spre deosebire de alţii, totalitarismul ,își arogă dreptul de a controla alegerea elementelor care trebuie reţinute."26 Numai că, în faţa istoriei, toţi avem dreptul de a ne aminti şi de a depune mărturie.

Jean-Yves Tadié remarcă propensiunea lui Kundera de a trece de la experienţa amară a prăbuşirii iluziilor comuniste la reflecţia lucidă pe care îşi fondează o filosofie a dictaturii. Caracteristica majoră a acestei dictaturi este uitarea pe care ea o impune, iar personajele din cărţile sale ajung să fie şterse aşa cum se întâmplă cu însăşi Istoria. ${ }^{27}$

În virtutea conceptului de continuitate şi coerenţă, între acţiunile din trecut, prezent şi viitor, logica totalitară îşi subordonează în întregime trecutul, uzând de el după bunul său plac. Fiind prin excelenţă exclusivistă, nefăcând niciodată compromisuri, logica sistemelor totalitare exclude $a$ priori orice alt punct de vedere ce îl contrazice pe al său.

Discursul ideologic al claselor conducătoare din societatea comunistă pe care o prezintă Kundera subordonează istoria propriilor sale interese, o modifică în funcţie de scopurile prezentului. Uzajul trecutului nu este niciodată unul inocent, ci el este regândit astfel ca să producă congruenţă cu momentul prezent şi să se poată constitui în rampă pentru viitor. Toate disonanţele, incongruenţele, inadvertenţele dintre realitatea faptelor trecutului şi orientarea dominantă din prezent sunt eliminate, iar elementele trecutului astfel simplificat sunt remodelate pentru a oferi suportul evenimentelor prezente. Validitatea trecutului este astfel pusă sub semnul întrebării. Istoria

${ }^{24}$ Cf. Tzvetan Todorov, Les Abus de la mémoire, Arléa, Paris, 2004, p.10.

25 «Les traces de ce qui a existé sont ou bien effacées, ou bien maquillées ou transformées »-ibid.

${ }^{26}$ « ils s'arrogent le droit de contrôler le choix des éléments à retenir. »-ibid., p. 15.

${ }^{27}$ Jean-Yves Tadié, Le roman au XXe siècle, Belfond, Paris, 1990, p. 190-191. 
modificată devine în comunism un discurs de manipulare, de legitimare în faţa noilor generaţii pe care le poate astfel influenţa.

\section{Bibliografie :}

CONnerton, Paul, How Modernity Forgets, Cambridge University Press, Cambridge, 2009.

Della Sala, Sergio (éd.), Forgetting, Psychology Press, Hove/New York, 2010.

GrenIER, Yvon,"Milan Kundera on Politics and the Novel", in History of Intellectual Culture, [University of Calgary], vol. 6, no 1, 2006, pp. 1-18.

KUNDERA, Milan, Le livre du rire et de l'oubli, traduit du tchèque par François Kérel, nouvelle édition revue par l'auteur, Gallimard, Paris, 1985.

KunDERA, Milan, L'ignorance, postface de François Ricard, Gallimard, Paris, 2005.

KUNDERA, Milan, L'immortalité, Gallimard, Paris, 1993.

KUNDERA, Milan, L'insoutenable légèreté de l'être, traduit du thcèque par François Kérel, Gallimard, Paris, 1984.

RICOEUR, Paul, La mémoire, l'histoire, l'oubli, Seuil, Paris, 2000.

SCHACTER, Daniel, Science de la mémoire. Oublier et se souvenir, traduit de l'anglais (Etats-Unis) par Christian Cler, Odile Jacob, Paris, 2003.

TADIÉ, Jean-Yves, Le roman au XXe siècle, Belfond, Paris, 1990.

TODOROv, Tzvetan, Les abus de la mémoire, Arléa, Paris, 2004. 